\title{
Idealized cloud-resolving simulations of land-atmosphere coupling over tropical islands
}

\author{
Chien-Ming $\mathrm{Wu}^{1, *}$ and Po-Yen Chen ${ }^{1,2}$ \\ ${ }^{1}$ Department of Atmospheric Sciences, National Taiwan University, Taipei City, Taiwan \\ ${ }^{2}$ Central Weather Bureau, Taipei City, Taiwan
}

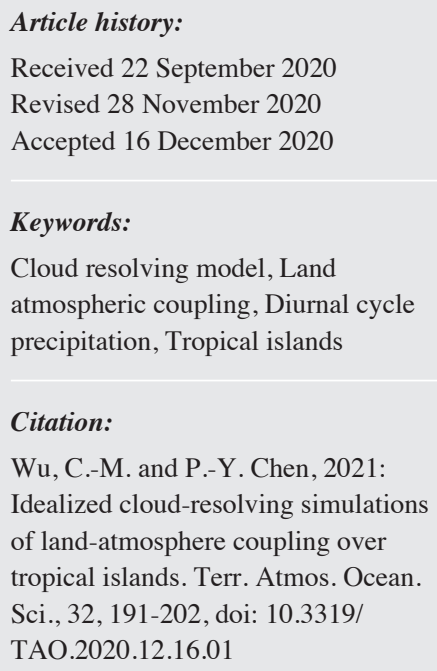

Wu, C.-M. and P.-Y. Chen, 2021: Idealized cloud-resolving simulations of land-atmosphere coupling over tropical islands. Terr. Atmos. Ocean. Sci., 32, 191-202, doi: 10.3319/ TAO.2020.12.16.01

\begin{abstract}
This study investigates the impact of land-atmosphere coupling (LAC) over tropical islands using a Vector-Vorticity equation cloud-resolving Model (VVM). Two sets of idealized simulations are performed with three land surface conditions (Urban, Pasture, and Grass). The first set considers direct LAC in which VVM is fully coupled with LSM. The second set of experiments eliminates direct LAC by prescribing surface fluxes in VVM, in which the high spatiotemporal variabilities are preserved from the fully coupled VVM/LSM. We can interpret the difference in convective systems' temporal and spatial evolution between the two sets of experiments as the LAC's impact. The results show that direct LAC enhances the diurnal amplitude and extreme precipitation under all land surface conditions. The impact of direct LAC is profound on the diurnal amplitude in the Urban experiment in which the sensible heat fluxes dominate. It produces $71 \%$ more precipitation with direct LAC than without. The result is due to the strong cold pool intensity by convective systems with large updraft core clouds in the Urban experiment. The mismatch between surface cooling and the convection in the experiments without direct LAC, on the other hand, prohibits further development of convection. In the Grass experiment, in which the latent heat fluxes dominate, the cold pool effects become less critical and have weaker impacts on convection development. Sensitivity experiments on free atmosphere moisture show that the dependency still holds except that the precipitation intensity is higher in a moister environment.
\end{abstract}

\section{INTRODUCTION}

The land-atmosphere interactions are crucial components of the diurnal evolution of precipitation over land (Betts 2009). The exchanges of heat and moisture between the land and the atmosphere can effectively modulate the surface energy budget. Variations in land properties can result in differences in total surface energy fluxes as well as the partition between the sensible and latent heat fluxes, which can affect the vertical structures and mixing processes of potential temperature and water vapor in the atmospheric boundary layer (ABL). The ABL properties, in turn, can affect the convective structure through vertical transport of the moist static energy. With the development of deep convection, the cold pools produced by precipitation and sustained by evaporation of rainwater can then feedback to

\footnotetext{
* Corresponding author

E-mail:mog@as.ntu.edu.tw
}

induce nonlinear changes in the land surface temperature and moisture and the development of stronger convective systems. These interactions play an important role in the hydrologic cycle and the surface energy budget and the transport of the air pollutant in the atmosphere (Anthes 1984; Avissar and Liu 1996; Betts et al. 1996; Betts and Silva Dias 2010). An accurate simulation of atmospheric processes requires a proper representation of the land-atmosphere interaction (see, e.g., an overview in Santanello et al. 2018).

Using the Tropical rainfall measuring mission (TRMM) Precipitation Radar (PR), Hamada et al. (2014) showed that extreme precipitation events occur mostly over the tropical islands and coastal areas. The Mechanism responsible for the extreme precipitation during the diurnal cycle over land is generally associated with cold pools. Saito et al. (2001) proposed that the importance of cold pools in producing diurnal intensity of precipitation in numerical simulations over 
tropical islands. In addition, Feng et al. (2015) proposed that intersecting cold pools can be twice as long as isolated cold pools, which can affect the development of convective systems. Besides the enhanced updrafts at the boundary of cold pools, deep convection initiated by the cold pools can promote the aggregation of convective systems. Drager and van den Heever (2017) proposed that land surface cooling by the precipitation effectively reduces the sensible heat fluxes and increases the latent heat fluxes creating the wet patch, which helps sustain the cold pool strength above. Gentine et al. (2016) showed that over the land surface, the heat fluxes underneath cold pools drastically impact the cold pool characteristics. Their results emphasize the importance of interactive surface fluxes when studying convection.

The treatment of land-atmosphere coupling in the general circulation model often occurs at the model's sub-grid scale processes. Interactions between convection and surface fluxes are treated in a bulk sense. On the other hand, the atmosphere models also use the grid-mean land surface fluxes to determine the convection and precipitation processes. The subgrid-scale interactions of the land surface and the meteorological fields are mostly ignored in this type of configuration. Therefore, the convective processes cannot distinguish the horizontal heterogeneous surface fluxes evolving into various convective systems. For example, $\mathrm{Wu}$ et al. (2015) demonstrated that the in-land breezes produce by large heterogeneous patches of surface fluxes modulate the diurnal evolution of precipitation in both precipitation initiation and its diurnal peak. In this study, we further emphasize that at different land surface types, the land-atmosphere coupling can affect the diurnal intensity, and in turn, affects the precipitation spectrum. We hypothesize that the fast surface processes/convection coupling can directly impact the diurnal intensity of the precipitation. Here the fast processes refer to the convective timescale compared to the slow evolution of the diurnal cycle. This hypothesis will be tested by experiments with/without land-atmosphere coupling over various land surface types. The model description and experiment setup are provided in section 2 . The role of LAC in the diurnal intensity is presented in section 3 . A summary and discussion are presented in section 4 .

\section{MODEL AND EXPERIMENTS}

\subsection{Vector Vorticity Equation Cloud-Resolving Model (VVM)}

The vector vorticity equation cloud-resolving model (VVM) used in this study was developed by Jung and Arakawa (2008) based on the three-dimensional anelastic vorticity equations. A unique aspect of this model is that the model predicts horizontal components of vorticity so that it is responsive to horizontal buoyancy gradient. A bulk three-phase cloud microphysics parameterization, including cloud droplets, ice crystals, rain, snow, and graupel, is ap- plied in this model (Krueger et al. 1995). The topography is implemented through the immersed boundary method (Wu and Arakawa 2011; Chien and Wu 2016). Noah land surface model (ver. 3.4.1) is implemented in VVM (Wu et al. 2019) to study the impact of land-atmosphere interaction over complex topography on afternoon thunderstorms (Wu et al. 2015; Kuo and Wu 2019). The model is also used to study the convective aggregation (Tsai and Wu 2017; Chen and $\mathrm{Wu} 2019 \mathrm{~b}$ ), the stratocumulus breakup (Tsai and $\mathrm{Wu}$ 2017), the effects of microphysics on precipitation extreme (Huang and Wu 2020), as well as the design of the unified parameterization for deep convection (Arakawa and $\mathrm{Wu}$ 2013; Wu and Arakawa 2014; Xiao et al. 2015).

\subsection{Experiment Setup}

The idealized setup of tropical islands follows Baker et al. (2001). The island is located at the center in the x-direction and uniformly distributed in the y-direction, occupying one-third of the domain. The rest of the domain is filled with ocean surface with fixed sea surface temperature, as illustrated in the top right panel of Fig. 1a. For simplicity, there is no topography over land area. The size of the islands corresponds to those over the Maritime Continent. We examined three land surface types in this study, namely Urban, Pasture, and Grass. A detailed description of the land types is presented in Table 1. For each experiment, we specify one land surface type. The land-atmosphere coupling over these three land surface conditions is evaluated by comparing the two sets of experiments similar to Chen (2017), Chen and Wu (2019a), and Wu et al. (2019). The first set of experiments representing direct LAC in which VVM is fully interactive with LSM (named Coupled). The second set of experiments eliminates direct LAC by prescribing surface properties in VVM from the fully coupled VVM/LSM (named Prescribed), including surface temperature, momentum fluxes, sensible, and latent heat fluxes. The evolution of surface forcing is basically the same as the Coupled experiment, and the high spatiotemporal variabilities are preserved, but the direct coupling is eliminated. The environmental features such as the sea breeze circulation will be similar in both sets of experiments, but in places where the LAC is strong, the non-linearly effects can grow fast and thus change the evolution of the convective systems. For example, when the strong convection develops, cold pools produced by evaporation of precipitation can provide mechanical lifting and further enhance convection development. The land surface beneath the cold pools can be cooled by the cold air and enhances the further development of cold pools. The interaction could, therefore, promote the development of more vigorous convection. In the Prescribed experiment, on the other hand, the precipitating area and the cold surface does not collocate with each other; the cold surface can suppress further development of convection. The difference between 
the two sets of experiments represents LAC's impact on the diurnal intensity of precipitation over tropical islands.

This study focuses on the impact of land atmospheric coupling on the diurnal intensity of precipitation among different land surface properties. Due to the complexity of convective processes, the environmental conditions are idealized. This approach is used by many cloud-resolving studies (Grabowski et al. 2006; Khairoutdinov and Randall 2006; Wu et al. 2009). For all the experiments, the horizontal model domain covers $512 \times 512 \mathrm{~km}^{2}$, with the grid spacing of $2 \mathrm{~km}$. The 34 vertical layers stretch from $100 \mathrm{~m}$ at the first model layer to $1 \mathrm{~km}$ at the model top, around 17 $\mathrm{km}$. The initial soundings follow Kuo and Wu (2019), representing a typical conditional unstable environment for the tropics that is horizontal homogeneously applied to the entire domain. The background wind is idealized with $3 \mathrm{~m} \mathrm{~s}^{-1}$ westerly uniformly in the vertical for the entire domain for initial conditions only. This initial background wind is essential to initiate surface fluxes in idealized simulations. The radiation calculates interactively with RRTMG (Iacono et al. 2008) by setting the solar radiation on 18 January over the tropics for all the experiments. The SST is prescribed for 302 $\mathrm{K}$. We add the temperature perturbation at the model's lowest level to create 6 ensemble members for each experiment. The output frequency is $10 \mathrm{~min}$, and the surface fluxes and precipitation are averaged over the $10 \mathrm{~min}$ while the wind and moisture fields are snapshots at the time of the output. Due to the initial perturbations, the random seeds in multigrid solvers, and the truncation errors in feeding the fluxes, the two experiments will not be identical. Under a conditionally unstable environment with weak winds, the perturbations grow fast, producing slightly different convection. However, the overall evolution of the diurnal cycle and the precipitation pattern is similar.

\subsection{Identification of Cold Pool Intensity}

To identify the intensity of the cold pool in the

(a)
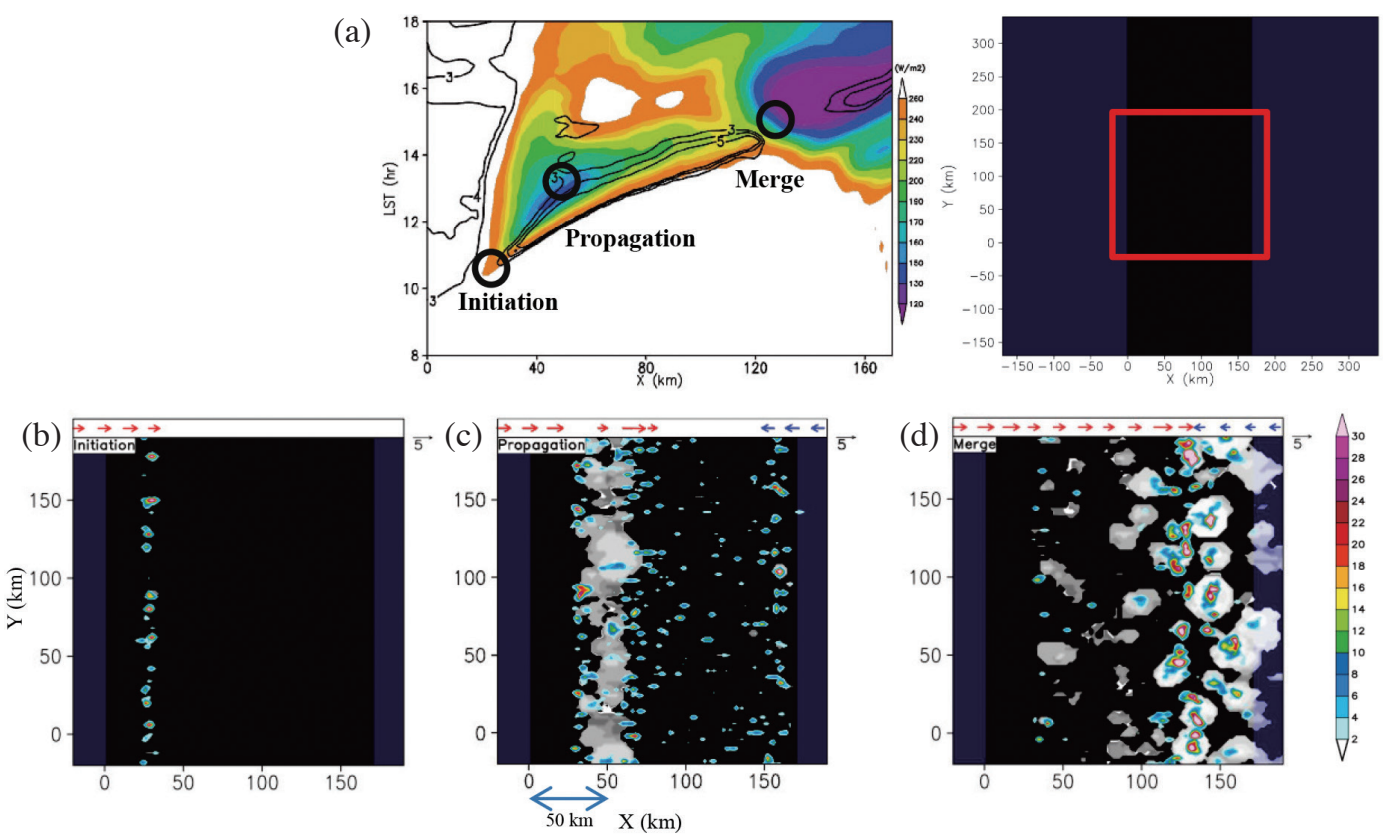

Fig. 1. (a) The top left panel presents the time evolution of near-surface u-wind below $300 \mathrm{~m}$ (contour), and the outgoing long wave radiation (shaded) averaged over Y-direction. The contour interval is $1 \mathrm{~m} \mathrm{~s}^{-1}$, and the shaded interval is $10 \mathrm{~W} \mathrm{~m}^{-2}$. The three stages are marked as open circles . The top right panel presents the entire simulation domain. The bottom panel presents the snapshots of (b) initiation, (c) propagation, and (d) merge stage over the red box. The precipitation (color shaded), out-going longwave radiation (grey shaded), and the near-surface wind. The color shaded interval is $2 \mathrm{~mm} \mathrm{hr}^{-1}$. The grey shaded interval is $5 \mathrm{~W} \mathrm{~m}^{-2}$. The unit of wind vector is $\mathrm{m} \mathrm{s}^{-1}$. See text for more details.

Table 1. Detail land surface setup for each experiment.

\begin{tabular}{c|cccccccc}
\hline Experiment & Land type & Land use & Soil type & $\begin{array}{c}\text { soil moisture } \\
\text { (volumetric) }\end{array}$ & porosity & Green fraction & albedo & Evaporative fraction \\
\hline Urban & urban & 1 & sand & -- & -- & 0.1 & 0.15 & 0.035 \\
Pasture & pasture & 2 & sand & 0.29 & 0.339 & 0.1 & 0.15 & 0.629 \\
Grass & grass & 7 & organic & 0.32 & 0.439 & 0.65 & 0.19 & 0.803 \\
\hline
\end{tabular}


simulation, we follow the method by Feng et al. (2015), which followed Tompkins (2001) using buoyancy $\left(b ; \mathrm{m} \mathrm{s}^{-2}\right)$. It is defined as:

$b=\frac{g\left(\theta_{v}-\overline{\theta_{v}}\right)}{\bar{\theta}_{v}}$

$\theta_{v}=\theta\left(1+0.608 q_{v}-q_{c}-q_{r}\right)$

where $g$ is the acceleration due to gravity, $\theta$ and $\theta_{v}$ are the potential temperature and virtual potential temperature, and $q_{v}, q_{c}$, and $q_{r}$ are the mass mixing ratio of water vapor, cloud condensate water, and rainwater, respectively. The overbar of $\theta_{v}$ indicates a horizontal domain mean in this study.

Cold pool intensity $\left(B ; \mathrm{m} \mathrm{s}^{-1}\right)$ is calculated using the vertical integral of buoyancy following Bryan and Parker (2010), which follows Rotunno et al. (1988):

$B=\sqrt{-2 \int_{0}^{h} b d z}$

where $b$ is the buoyancy, and $h$ is the depth of the cold pool. In this study, we follow the threshold used in Feng et al. (2015) that the depth of the cold pool $(h)$ is at which the $b$ first exceeds $-0.003\left(\mathrm{~m} \mathrm{~s}^{-1}\right)$ from the land surface.

\section{RESULTS}

The time evolution of outgoing longwave radiation (OLR) and near-surface horizontal wind fields for the Urban case is presented in Fig. 1a. We take the average over $y$-direction and focus on the land area only. Three stages of convective development can be identified, namely initiation, propagation, and merge stages. During the initiation stage (Fig. 1b), deep convective clouds develop at around $40 \mathrm{~km}$ inland area. The thermally driven convection is small in size with no particular anvil clouds. During the propagation stage (Fig. 1c), large anvil clouds develop as demonstrated by the horizontal distribution of ice clouds as well as the low domain averaged OLR. Stronger precipitation is generated through the convective system and produces strong downdrafts as well as strong cold pools.

Along with the background sea breeze circulation, the outflow generates new convective cells inland toward the east. At around 14:00 LST, the sea breezes from both sides merge and produce strong convective systems at about $130 \mathrm{~km}$ (Fig. 1d). The intensity of precipitation is highest at this moment, and it's called the merge stage in this study. The width of the islands is narrow enough so that the sea breezes from both sides can be merged inland. This feature corresponds well with the observational studies (Saito et al. 2001) over the Maritime Continent even though the simulations are highly idealized.
Figure 2 presents the time evolution of boundary layer characteristics over land for all experiments. The shaded area represents the standard variation among 6 ensemble members. The precipitation begins at the initiation stage (around 10:00 LST) and peak during the merge stage (around 15:00 to 16:00 LST) with a magnitude of $1.5-1.7 \mathrm{~mm} \mathrm{hr}^{-1}$ (Fig. 2a). The total surface fluxes (sensible plus latent heat) are very different among various land types, with Grass (Urban) being the highest (lowest) (Fig. 2b). With enough solar radiation, the land surface is able to transform the energy through evapotranspiration effectively over the Grass compared to the Urban. The peak time of precipitation is a few hours later than that of the surface fluxes, which generally peaks after the merge stage (black dots) for each experiment. We define the diurnal intensity of precipitation by the precipitation rate averaged over the peak hour. The results show that even though the evolution of diurnal precipitation is different, the diurnal intensity is comparable for each experiment with its deviation around $0.2 \mathrm{~mm} \mathrm{hr}^{-1}$. A possible mechanism is proposed below: as the surface heats up by the solar radiation, the Urban area transforms most of its solar energy to sensible heat producing a deep boundary layer $(1 \mathrm{~km})$ compared to Pasture $(0.75 \mathrm{~km})$ and Grass $(0.5 \mathrm{~km})$ as illustrated in Fig. 2c. Correspondingly, the surface parcel lifting condensation level (LCL) is highest over the Urban area (Fig. 2d). Given the idealized setting over tropical islands, the near-surface moist static energy (Fig. 2e) demonstrates that the convective instability is large for all experiments with difference within $2 \mathrm{~K}$, suggesting that stronger convection can develop when lifted. The cold pool is driven by the downdraft and sustained by evaporative cooling of rainwater; a dry and deep boundary layer enhances the evaporative cooling of rainwater that is favorable for cold pool formation over the Urban area. The cold pools can provide an additional lifting mechanism for the convection to develop. Characteristics of boundary layer evolution for the Prescribed experiments are presented in Fig. 3. The overall evolution is very similar to the Coupled experiments except for the diurnal evolution of precipitation, suggesting that the two sets of experiments do have similar surface forcing, but when the fast land atmospheric coupling dominates, the precipitation evolution can be different. Note that the landatmospheric coupling has little impact on the sea-breeze circulation. Therefore, the merge stage occurs roughly the same time for both the Coupled and Prescribed experiments. Following Feng et al. (2015), we can estimate the cold pool intensity as vertical integrated stronger negative buoyancy directly from the CRM. The cold pool intensity is the strongest for the Urban experiment before the merge stage (Fig. 2f), suggesting that even though the total energy fluxes are weaker over Urban compared with Grass, strong cold pools can promote the development of organized convective systems that can compensate the energy deficiency in producing stronger diurnal intensity. 

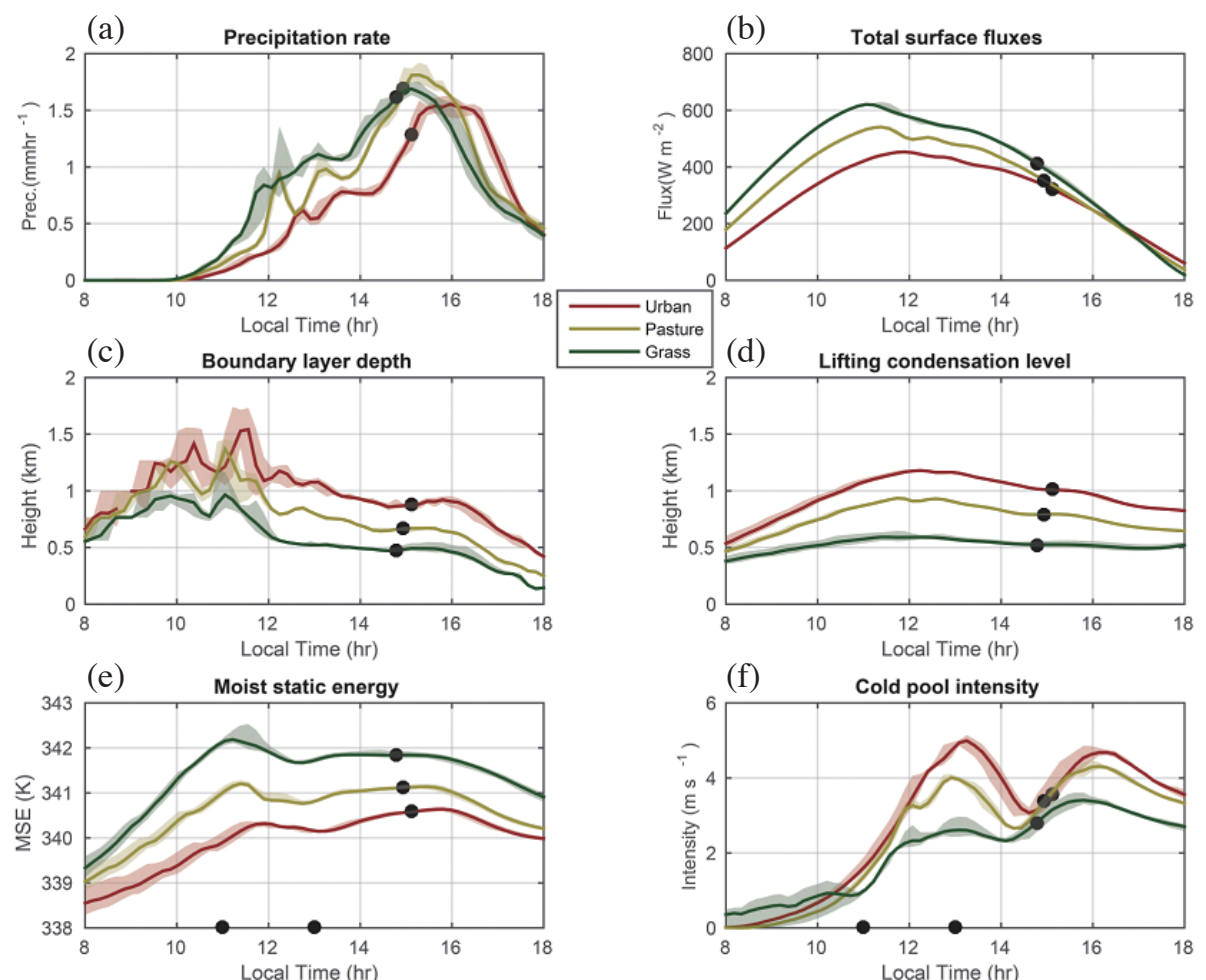

Fig. 2. Diurnal evolution averaged over the land area for the Coupled experiments for (a) precipitation (mm hr-1), (b) total surface (sensible plus latent heat) fluxes $\left(\mathrm{W} \mathrm{m}^{-2}\right)$, (c) boundary layer depth $(\mathrm{km})$, (d) lifting condensation level (LCL) (km), (e) near-surface moist static energy divided by $\mathrm{C}_{\mathrm{p}}(\mathrm{K})$ and (f) cold pool intensity $\left(\mathrm{m} \mathrm{s}^{-1}\right)$ for urban, pasture, and grass experiments, respectively. The shading represents the standard deviation for 6 ensemble members. Black dots on the X-axis represent initiation and propagation stages, respectively. Black dots on the lines represent merge stages for each experiment. See text for more details.
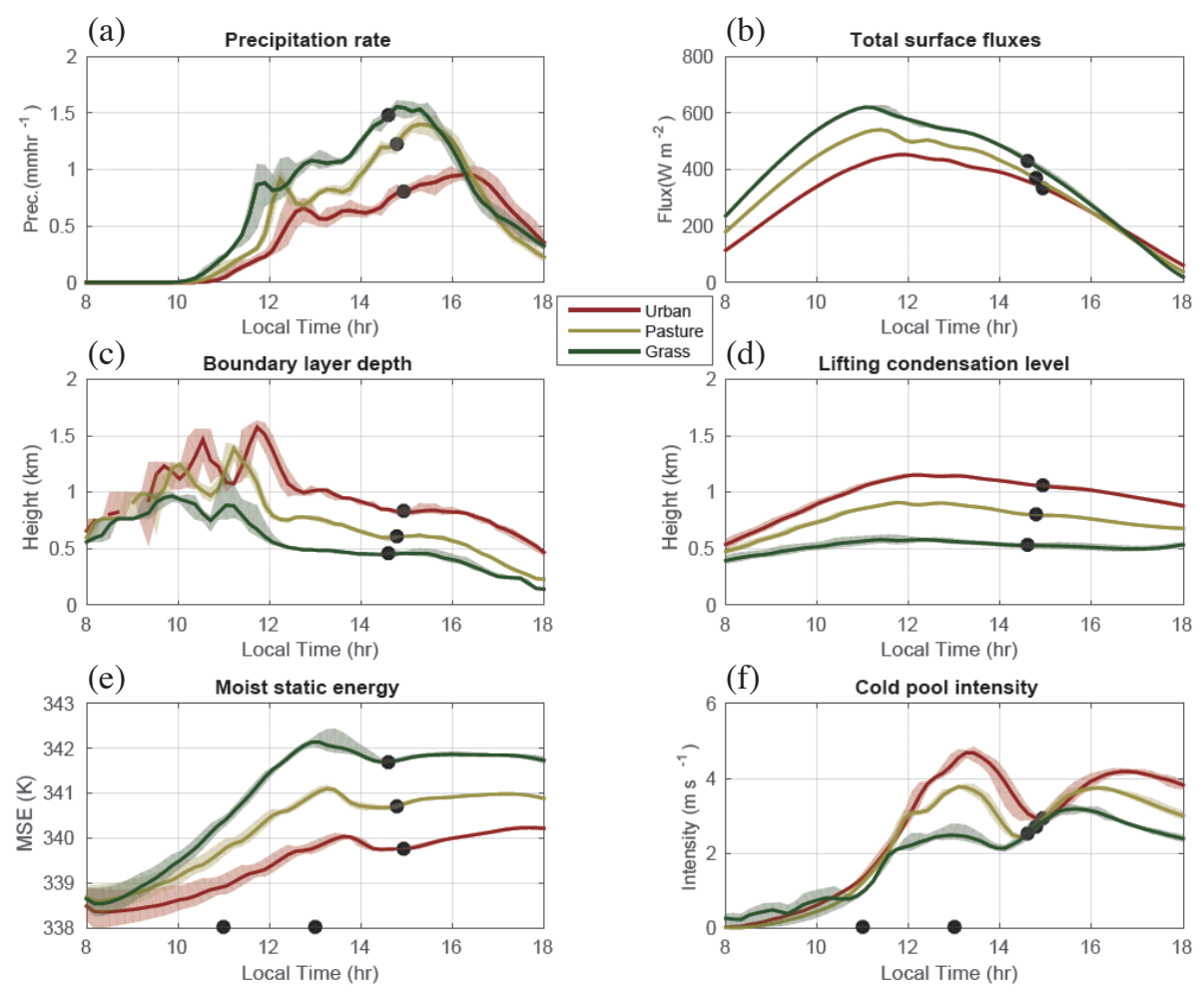

Fig. 3. Same as Fig. 2 except for Prescribed experiments. 
To confirm this hypothesis, we present vertical profiles snapshots of the convective clouds and the boundary layer structure during the merge stage (Fig. 4). Over the Urban area, the convective system (grey shading) with strong updrafts (red contours) occurs right above the strong convergence of boundary layer flows (red and light green shading in the boundary layer) associated with strong cold pools (blue shaded in the boundary layer). The major difference among the three coupled experiments is that the vertical extension of the cold pools in the boundary layer becomes weaker from Urban to Grass. This is due to the fact that the boundary layer becomes moister in Pasture and Grass supported by stronger latent fluxes, which makes the boundary layer less favorable for the cold pools. This feature can be visualized by the vertical steepness of the cold pool fronts around $130 \mathrm{~km}$ for all experiments. The updraft is also less concentrated over Grass than Urban and Pasture, indicated by the figure's red contours. The tight coupling between the boundary layer cold pools and the convective system over the Urban shows that the diurnal intensity is controlled by the organized convection associated with the cold pools. By turning off the direct coupling between the surface and the boundary layer atmosphere, the convection is generally weaker, as demonstrated in the prescribed experiments (right panel of Fig. 4) during the merge stage. The cloud structure is less organized with weaker updrafts as the coupling between the land surface and the boundary layer departs. The systematic dependence of cold pool fronts in the Coupled experiments disappears and leaves only the signals of the synoptic sea breezes convergence in the Prescribed experiments. LAC has the largest impact over Urban with the diminishing convective cores and the anvil clouds. The impact of LAC on diurnal intensity in our idealized experiments can be summarized in Fig. 5. LAC has the largest influence over the Urban area with a magnitude of $0.6 \mathrm{~mm} \mathrm{hr}^{-1}$. Its effect systematically decreases when the land surface type transit from Urban to Pasture to Grass as the latent heat fluxes increase with the land type as well as the increase of total surface fluxes. Over the Grass area, the impact of LAC is negligible with a magnitude of around $0.1 \mathrm{~mm} \mathrm{hr}^{-1}$. Note that the difference of diurnal intensity among different land types is small in the Coupled experiments (within $0.2 \mathrm{~mm} \mathrm{hr}^{-1}$ ).

We hypothesize that the cause of such a difference in diurnal intensity is mainly due to the convective system with stronger updrafts that can produce extreme precipitation over a short period of time. Following Tsai and $\mathrm{Wu}$ (2017), we calculate the size distribution of convective core clouds for all the experiments. A cloud object is defined by connecting cloudy pixels (cloud liquid plus cloud ice greater than $10^{-5} \mathrm{~kg} \mathrm{~kg}^{-1}$ ) using a six-connected segmentation method from the model output. Within the cloud object, we can further identify the convective core clouds by subjectively constrain the cloud object to have a cloud base below $2 \mathrm{~km}$ and the updraft velocity greater than $0.5 \mathrm{~m} \mathrm{~s}^{-1}$ as demonstrated in Fig. 6. The precipitation associated with the convective core clouds can also be identified by projecting the 3D object to the surface precipitation area. The probability distribution for all experiments is presented in Fig. 7. The precipitation distribution is similar among all experiments, with its frequency decreases logarithmically as the precipitation becomes stronger. Some precipitation events can reach $100 \mathrm{~mm} \mathrm{hr}^{-1}$, but they are infrequent (less than $10^{-5}$ ). Over Urban, the Coupled experiment produces overall more intense precipitation events compared to the Prescribed experiment. The difference becomes more evident in the more extreme precipitation events. From Urban to Grass, it is clear that the systematic difference in the large precipitation frequency weakens, suggesting the impact of LAC weakens. Such dependency leads us to attribute the precipitation events to the scale of the convective core clouds, as presented in the right panel of Fig. 7. The distribution is presented in a log-log plot in which the frequency of convective core clouds decreases linearly as the increase of cloud size when the size is greater than $10^{2} \mathrm{~km}^{3}$. The largest size of convective core clouds is about $10^{4} \mathrm{~km}^{3}$, roughly corresponds to a $30-\mathrm{km}$ wide updraft on a horizontal scale. In the Coupled experiment, the frequency becomes flat with a second peak near a core size of $10^{4} \mathrm{~km}^{3}$. As discussed in Tsai and $\mathrm{Wu}$ (2017), this distribution represents the convective aggregation in the model. In the Prescribed experiments, the second peak of core size disappears, leaving the power-law dependence of cloud size frequency. The difference in precipitation and convective core size spectrum demonstrates that the impact of LAC on diurnal intensity is caused by these large convective clouds associated with the cold pools during the merge stage.

We further examine the impact of LAC under various free atmosphere moisture. A series of sensitivity experiments are performed by modulating the free atmosphere relative humidity (above $4 \mathrm{~km}$ ) for $20 \%$ for all experiments. The results (Fig. 8) show that the diurnal cycle of precipitation in the Coupled experiment increases with the increase of free atmosphere moisture regardless of the surface land types. The impact of LAC on diurnal intensity over various land types remains similar. LAC's impact on diurnal intensity also shows a strong dependence on free atmosphere moisture over Urban and Pasture compared to Grass. LAC's impact is the largest over Urban area when the environment is very moist, suggesting that the cold pool mechanism proposed above could produce more extreme precipitation under a favorable environment. Over the Grass area, however, LAC's impact is almost the same, showing that the development of convection relies more on conditional instability. The cold pools do not play an essential role over Grass.

\section{SUMMARY AND DISCUSSION}

This study investigates the impact of land-atmosphere 

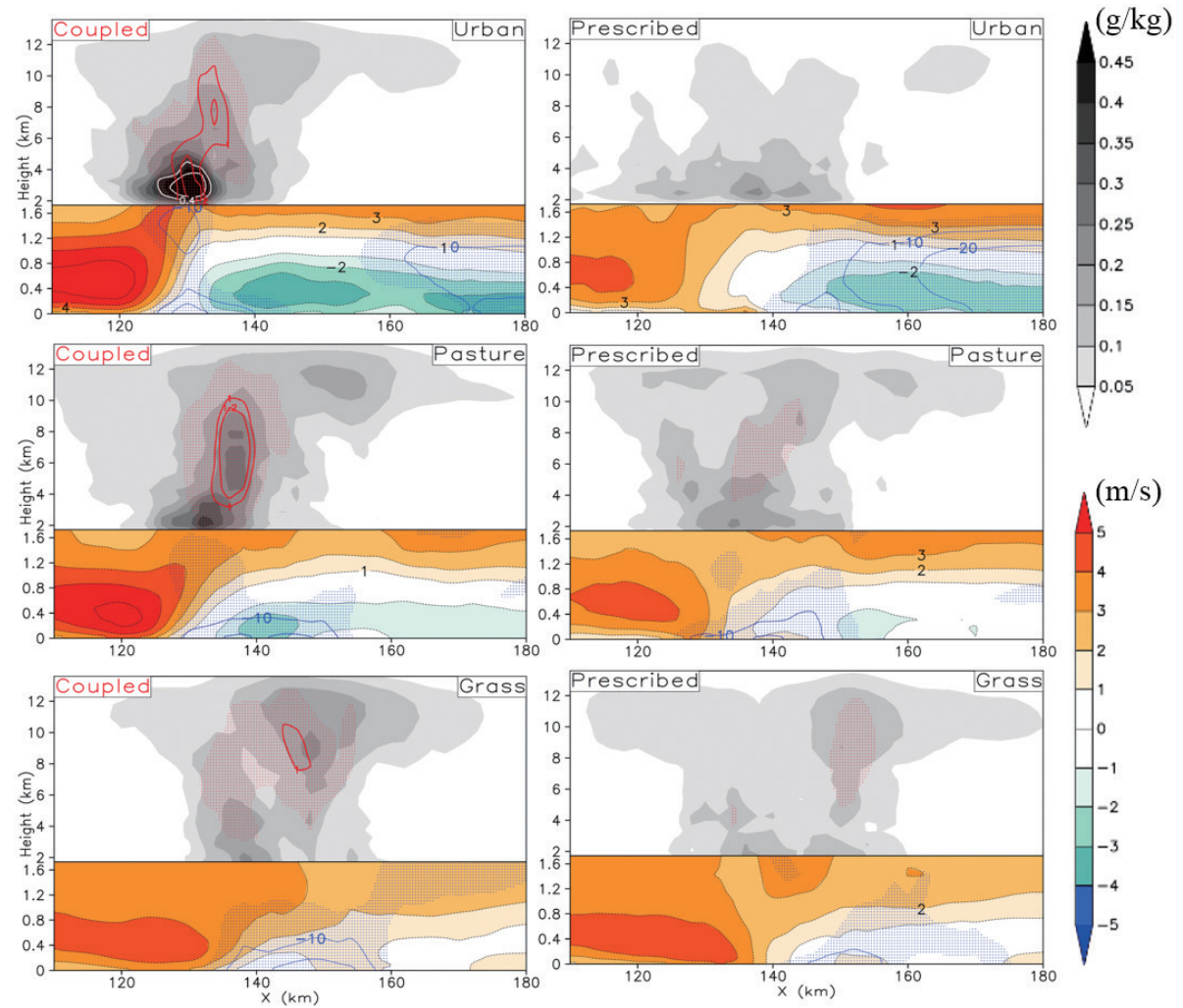

Fig. 4. The vertical structure of the boundary layer and convective systems averaged over the y-direction during the merge stage. Grey shading and white contours represent the clouds (mixing ratio of cloud and ice); red dots and contours represent vertical velocity greater than $0.5 \mathrm{~m} \mathrm{~s}^{-1}$; orange shading and black contour represent the boundary layer wind in the $\mathrm{x}$-direction and the blue dots and contours represent the cold pools in the boundary layer which is defined as the negative buoyancy lower than $-0.003 \mathrm{~m} \mathrm{~s}^{-2}$.

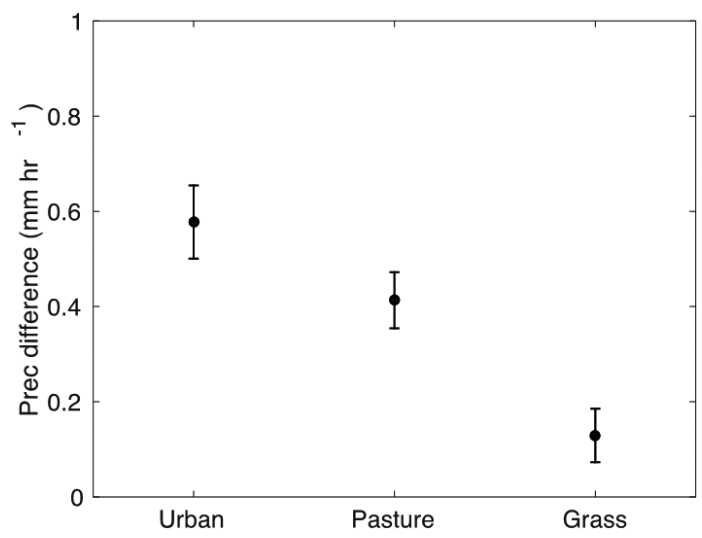

Fig. 5. The impact of land-atmosphere coupling on diurnal intensity for three different land surface types. The unit is $\mathrm{mm} \mathrm{hr}{ }^{-1}$. The bar represents the standard deviation among 6 ensemble members. See the text for more discussion. 


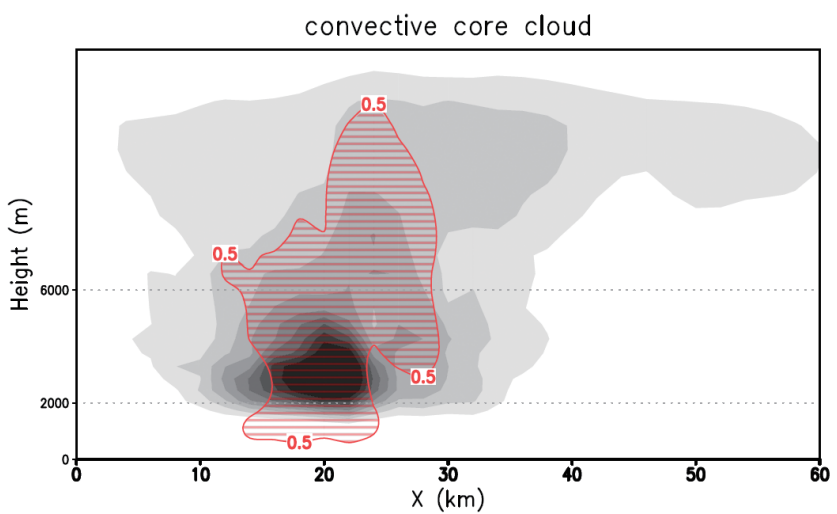

Fig. 6. The schematic diagram for the convective core clouds. The convective core clouds are defined as the connected cloudy pixels with a vertical velocity greater than $0.5 \mathrm{~m} \mathrm{~s}^{-1}$.
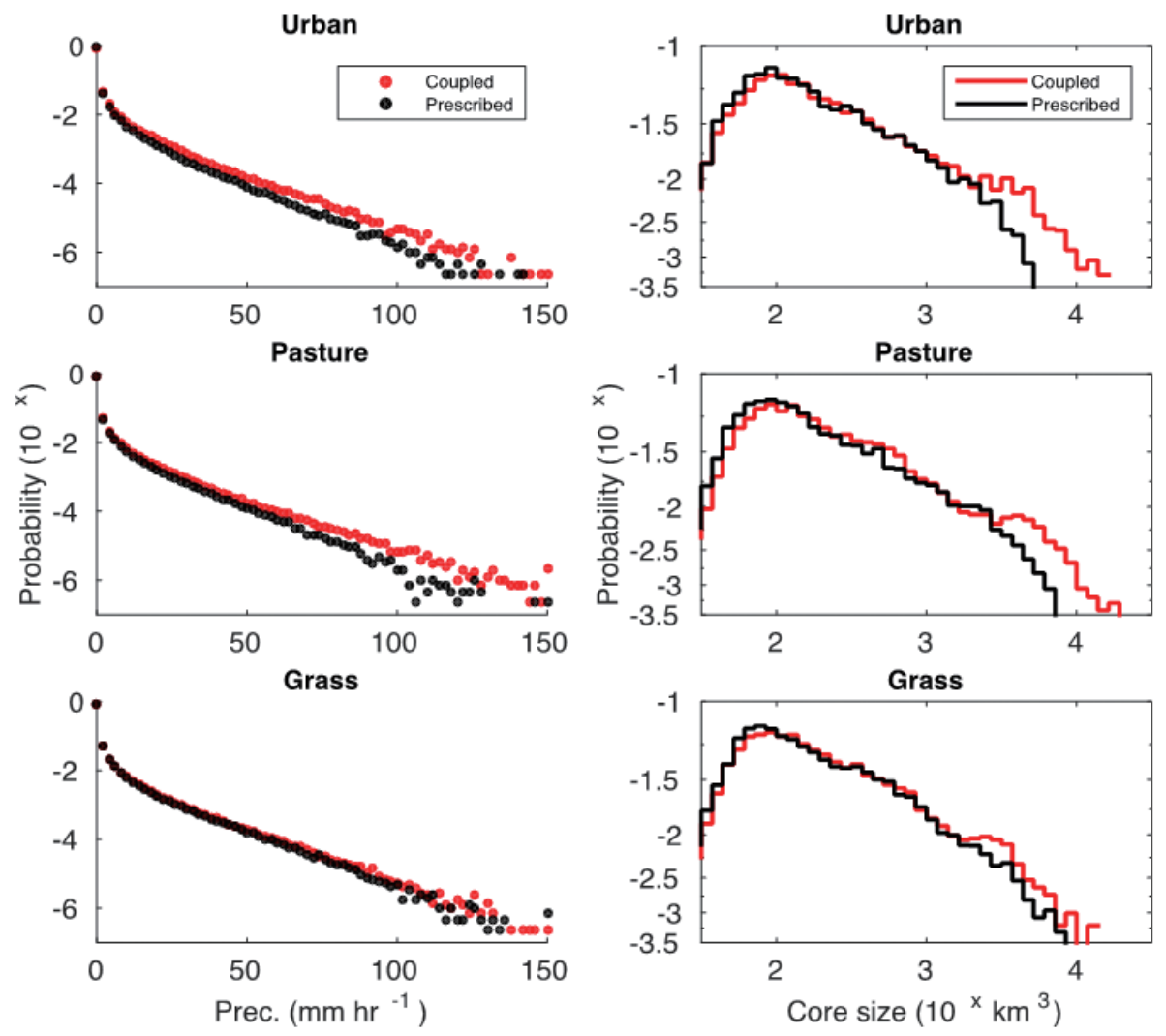

Fig. 7. Left panels represent the precipitation spectrum for urban, pasture, and grass experiments. Red and black dots represent experiments with (Coupled) and without (Prescribed) direct land-atmosphere coupling. The unit is $\mathrm{mm} \mathrm{hr}^{-1}$. Right panels represent convective core cloud size distribution for urban, pasture, and grass. Red and black lines represent experiments with (Coupled) and without (Prescribed) direct land-atmosphere coupling. The unit is $\mathrm{km}^{3}$. Here we take the data from $2 \mathrm{pm}$ to $6 \mathrm{pm}$ in all cases. 

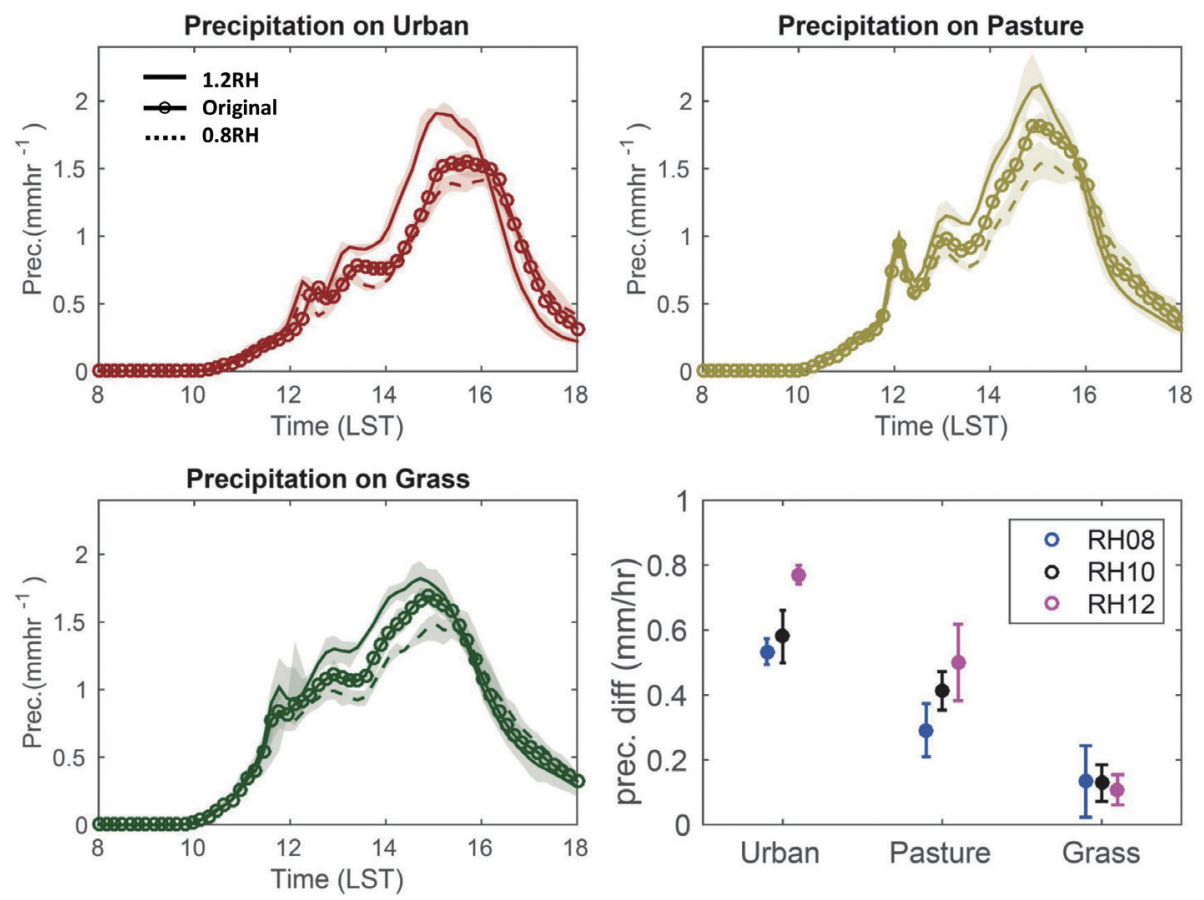

Fig. 8. Diurnal evolution of precipitation over land for free troposphere moisture sensitivity experiments. RH08, RH10, and RH12 represent relative humidity above $4 \mathrm{~km}$, which is multiplied by $0.8,1.0$, and 1.2 , respectively, from the initial conditions. Gray shaded represents the standard variation for 6 ensemble members. Same as Fig. 5, the impact of LAC on diurnal intensity is presented in the bottom right panel.

coupling (LAC) on the diurnal intensity of precipitation over a tropical island. Idealized simulations are performed with three land surface conditions (Urban, Pasture, and Grass) using a three-dimensional Vector Vorticity equation cloud-resolving Model (VVM) coupled with the Noah Land Surface Model (LSM). The simulations are idealized as flat land areas occupying one-third of the model domain uniformly in the y-direction. The impact of LAC on the diurnal intensity of precipitation is evaluated through two sets of experiments. The first set considers direct LAC in which VVM is fully coupled with LSM. The second set of experiment eliminates direct LAC by prescribing surface fluxes in VVM, in which the high spatiotemporal variabilities are preserved from the fully coupled VVM/LSM.

The results show that the diurnal intensity is comparable among various land surface types, while maximum total surface energy fluxes differ roughly $150 \mathrm{~W} \mathrm{~m}^{-2}$. This is caused by the convective systems are dominated by the cold pools over Urban while moisture fluxes dominate the convective development over Grass. Both convective systems generate strong precipitation when sea-breezes merge in the afternoon. LAC causes stronger diurnal amplitude and extreme precipitation under all land surface conditions. The impact of LAC is profound on the diurnal amplitude with the Urban experiment, which produces $71 \%$ more precipitation showing that the impact of LAC depends on the convective systems. Sensitivity experiments on free atmosphere moisture show that the dependency still holds ex- cept that the precipitation intensity is higher in a moister environment. These findings imply that the diurnal intensity of precipitation, as well as the extreme events, can be more sensitive to LAC over tropical islands through processes such as Urbanization or deforestation, which can be underestimated in large-scale models.

The role of cold land surface area in prohibiting the development of convection is demonstrated in Fig. 9. The cold land surface area, together with the cold pool in the atmosphere, is strongly coupled over the Urban area due to the strong sensible heat flux changes there. The coupling is weak over the Grass area. Spatial correlation between the cold pools and the surface cold area supports this dependency (not shown). As discussed in Drager and van den Heever (2017), the cold surface patch helps to maintain the cold pools in the Coupled experiment over Urban.

On the other hand, the cold surface prohibits the development of a convective system in the prescribed experiments. A schematic diagram that summarized LAC's impact on diurnal intensity over different land types is presented in Fig. 10. The idealized experiments emphasize the role of land-atmosphere coupling where the convective systems during the sea breeze convergence is the main cause of the diurnal intensity. The real world is full of weather systems and waves that can affect the diurnal cycle, and the results discussed in this study can still hold by composite analyses to filter out the noises. This study highlights that the organization of convective systems can compensate for 

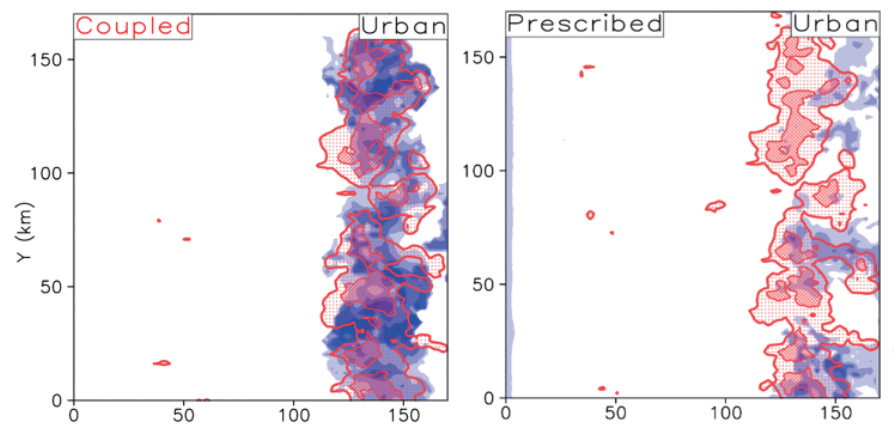

$(\mathrm{m} / \mathrm{s})$
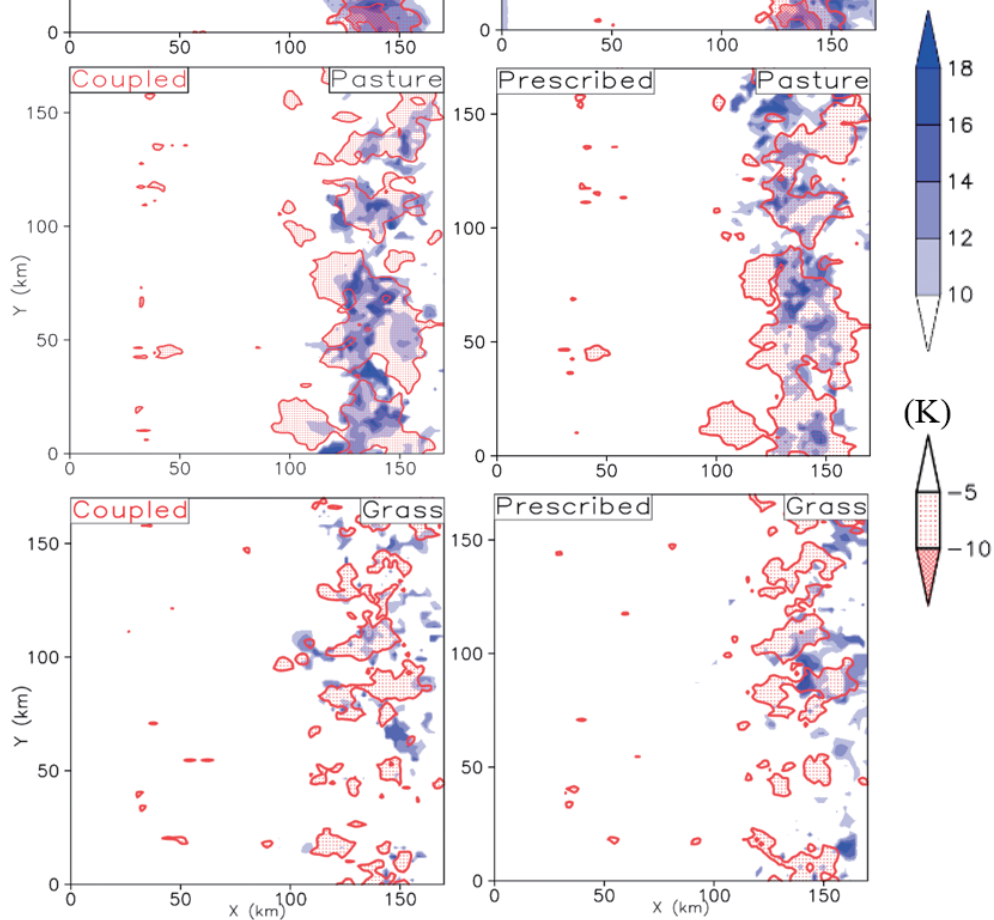

(K)

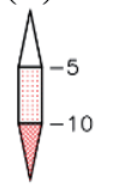

Fig. 9. Snapshots of the location of cold pools (blue) and surface cold region (red) for all experiments during the merge stage.

\section{Coupled}

Strong core clouds through cold pool dynamics

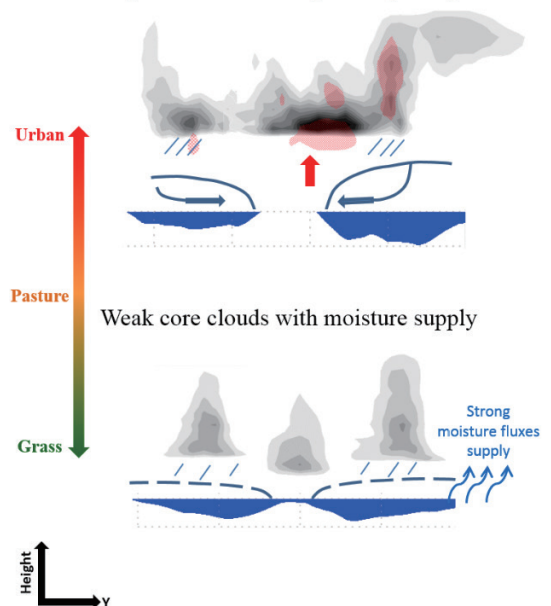

\section{Prescribed}

Weak core clouds without moisture supply

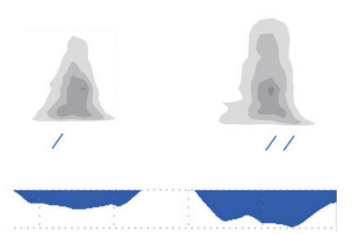

Weak core clouds with moisture supply

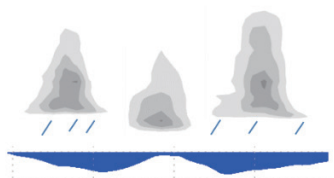

Fig. 10. The schematic diagram for the impact of land-atmosphere coupling on diurnal intensity over tropical islands under different land surface conditions. 
the decrease of total energy and the potential of considering such a process on the impact of diurnal intensity in the global models.

Acknowledgements The model results of VVM used in this study can be downloaded directly from http://140.112.67.90/ land atmpsphere coupling/. We thank TIMS for providing computation resources and data storage. The authors are supported by Taiwan's MOST through Grant 107-2111-M002-010-MY4 and Academia Sinica through Grant AS-TP109-M11 to National Taiwan University.

\section{REFERENCES}

Anthes, R. A., 1984: Enhancement of convective precipitation by mesoscale variations in vegetative covering in semiarid regions. J. Appl. Meteorol. Climatol., 23, 541-554, doi: 10.1175/1520-0450(1984)023<0541:EOCPBM $>2.0 . C O ; 2$. [Link]

Arakawa, A. and C.-M. Wu, 2013: A Unified Representation of Deep Moist Convection in Numerical Modeling of the Atmosphere. Part I. J. Atmos. Sci., 70, 19771992, doi: 10.1175/JAS-D-12-0330.1. [Link]

Avissar, R. and Y. Liu, 1996: Three-dimensional numerical study of shallow convective clouds and precipitation induced by land surface forcing. J. Geophys. Res., 101, 7499-7518, doi: 10.1029/95jd03031. [Link]

Baker, R. D., B. H. Lynn, A. Boone, W.-K. Tao, and J. Simpson, 2001: The Influence of Soil Moisture, Coastline Curvature, and Land-Breeze Circulations on SeaBreeze-Initiated Precipitation. J. Hydrometeorol., 2, 193-211, doi: 10.1175/1525-7541(2001)002<0193:TIOSMC $>2.0 . \mathrm{CO} ; 2$. [Link]

Betts, A. K., 2009: Land-surface-atmosphere coupling in observations and models. J. Adv. Model. Earth Syst., 1, doi: 10.3894/james.2009.1.4. [Link]

Betts, A. K. and M. A. F. Silva Dias, 2010: Progress in understanding land-surface-atmosphere coupling from LBA research. J. Adv. Model. Earth Syst., 2, doi: 10.3894/james.2010.2.6. [Link]

Betts, A. K., J. H. Ball, A. C. M. Beljaars, M. J. Miller, and P. A. Viterbo, 1996: The land surface-atmosphere interaction: A review based on observational and global modeling perspectives. J. Geophys. Res., 101, 72097225, doi: 10.1029/95jd02135. [Link]

Bryan, G.H. and M.D.Parker, 2010: Observations of a squall line and its near environment using high-frequency Rawinsonde launches during VORTEX2. Mon. Weather Rev., 138, 4076-4097, doi: 10.1175/2010MWR3359.1. [Link]

Chen, B.-Y., 2017: The Impact of land-atmosphere interactions on the diurnal intensity of precipitation over tropical islands. Master Thesis, Department of Atmospheric Sciences, National Taiwan University, Taipei
Caity, Taiwan. (in Chinese)

Chen, B.-Y. and C.-M. Wu, 2019a: The Impact of land atmosphere interactions on the diurnal intensity of precipitation over tropical islands. Atmos. Sci., 47, 120-138, doi: 10.3966/025400022019064702001. (in Chinese) [Link]

Chen, Y.-T. and C.-M. Wu, 2019b: The role of interactive SST in the cloud-resolving simulations of aggregated convection. J. Adv. Model. Earth Syst., 11, 3321-3340, doi: 10.1029/2019MS001762 [Link]

Chien, M.-H. and C.-M. Wu, 2016: Representation of topography by partial steps using the immersed boundary method in a vector vorticity equation model (VVM). J. Adv. Model. Earth Syst., 8, 212-223, doi: 10.1002/2015ms000514. [Link]

Drager, A. J. and S. C. van den Heever, 2017: Characterizing convective cold pools. J. Adv. Model. Earth Syst., 9, 1091-1115, doi: 10.1002/2016ms000788. [Link]

Feng, Z., S. Hagos, A. K. Rowe, C. D. Burleyson, M. N. Martini, and S. P. de Szoeke, 2015: Mechanisms of convective cloud organization by cold pools over tropical warm ocean during the AMIE/DYNAMO field campaign. J. Adv. Model. Earth Syst., 7, 357-381, doi: 10.1002/2014ms000384. [Link]

Gentine, P., A. Garelli, S.-B. Park, J. Nie, G. Torri, and Z. Kuang, 2016: Role of surface heat fluxes underneath cold pools. Geophys. Res. Lett., 43, 874-883, doi: 10.1002/2015gl067262. [Link]

Grabowski, W. W., P. Bechtold, A. Cheng, R. Forbes, C. Halliwell, M. Khairoutdinov, S. Lang, T. Nasuno, J. Petch, W.-K. Tao, R. Wong, X. Wu, and K.-M. Xu, 2006: Daytime convective development over land: A model intercomparison based on LBA observations. Q. J. R. Meteorol. Soc., 132, 317- 344, doi: 10.1256/ qj.04.147. [Link]

Hamada, A., Y. Murayama, and Y. N. Takayabu, 2014: Regional Characteristics of Extreme Rainfall Extracted from TRMM PR Measurements. J. Clim., 27, 81518169, doi: 10.1175/jcli-d-14-00107.1. [Link]

Huang, J.-D. and C.-M. Wu, 2020: Effects of Microphysical Processes on the Precipitation Spectrum in a Strongly Forced Environment. Earth and Space Science, 7, doi: 10.1029/2020ea001190. [Link]

Iacono, M. J., J. S. Delamere, E. J. Mlawer, M. W. Shephard, S. A. Clough, and W. D. Collins, 2008: Radiative forcing by long-lived greenhouse gases: Calculations with the AER radiative transfer models. J. Geophys. Res., 113, D13103, doi: 10.1029/2008JD009944. [Link]

Jung, J.-H. and A. Arakawa, 2008: A three-dimensional anelastic model based on the vorticity equation. Mon. Weather Rev., 136, 276-294, doi: 10.1175/2007mwr2095.1. [Link]

Khairoutdinov, M. and D. Randall, 2006: High-resolution simulation of shallow-to-deep convection transition 
over land. J. Atmos. Sci., 63, 3421- 3436, doi: 10.1175/ JAS3810.1. [Link]

Krueger, S. K., Q. Fu, K. N. Liou, and H.-N. S. Chin, 1995: Improvements of an ice-phase microphysics parameterization for use in numerical simulations of tropical convection. J. Appl. Meteorol., 34, 281-287, doi: 10.1175/1520-0450-34.1.281. [Link]

Kuo, K.-T. and C.-M. Wu, 2019: The precipitation hotspots of afternoon thunderstorms over the Taipei Basin: Idealized numerical simulations. J. Meteorol. Soc. Jpn., 97, 501-517, doi: 10.2151/jmsj.2019-031. [Link]

Rotunno, R., J. B. Klemp, and M.L. Weisman, 1988: A theory for strong, long-lived squall lines. J. Atmos. Sci., 45, 463-485, doi: 10.1175/1520-0469(1988)045<0463:ATFSLL > 2.0.CO;2. [Link]

Saito, K., T. Keenan, G. Holland, and K. Puri, 2001: Numerical Simulation of the Diurnal Evolution of Tropical Island Convection over the Maritime Continent. Mon. Weather Rev., 129, 378-400, doi: 10.1175/1520-0493(2001)129<0378:NSOTDE > 2.0. CO;2. [Link]

Santanello, J. A., Dirmeyer, P. A. Dirmeyer, C. R. Ferguson, K. L. Findell, A. B. Tawfik, A. Berg, M. Ek, P. Gentine, B. P. Guillod, C. van Heerwaarden, J. Roundy, and V. Wulfmeyer, 2018: Land-Atmosphere Interactions: The LoCo Perspective. Bull. Amer. Meteorol. Soc., 99, 1253-1272, doi: 10.1175/bams-d-17-0001.1. [Link]

Tompkins, A. M., 2001: Organization of Tropical Convection in Low Vertical Wind Shears: The Role of Cold Pools. J. Atmos. Sci., 58, 1650-1672, doi: 10.1175/1520-0469(2001)058<1650:OOTCIL >2.0. CO;2. [Link]
Tsai, W.-M. and C.-M. Wu, 2017: The environment of aggregated deep convection. J. Adv. Model. Earth Syst., 9, 2061-2078, doi: 10.1002/2017ms000967. [Link]

Wu, C.-M. and A. Arakawa, 2011: Inclusion of Surface Topography into the Vector Vorticity Equation Model (VVM). J. Adv. Model. Earth Syst., 3, M04002, doi: 10.1029/2011ms000061. [Link]

Wu, C.-M. and A. Arakawa, 2014: A Unified Representation of Deep Moist Convection in Numerical Modeling of the Atmosphere. Part II. J. Atmos. Sci., 71, 20892103, doi: 10.1175/jas-d-13-0382.1. [Link]

Wu, C.-M., B.Stevens, and A. Arakawa, 2009: What controls the transition from shallow to deep convection? J. Atmos. Sci., 66, 1793-1806, doi: 10.1175/2008jas2945.1. [Link]

Wu, C.-M., M.-H. Lo, W.-T. Chen, and C.-T. Lu, 2015: The impacts of heterogeneous land surface fluxes on the diurnal cycle precipitation: A framework for improving the GCM representation of land-atmosphere interactions. J. Geophys. Res., 120, 3714-3727, doi: 10.1002/2014jd023030. [Link]

Wu, C.-M., H.-C. Lin, F.-Y. Cheng, and M.-H. Chien, 2019: Implementation of the land surface processes into a vector vorticity equation model (VVM) to study its impact on afternoon thunderstorms over complex topography in Taiwan. Asia-Pac.J. Atmos. Sci., 55, 701-717, doi: 10.1007/s13143-019-00116-x. [Link]

Xiao, H., W. I. Gustafson, S. M. Hagos, C.-M. Wu, and H. Wan, 2015: Resolution-dependent behavior of subgrid-scale vertical transport in the Zhang-McFarlane convection parameterization. J. Adv. Model. Earth Syst., 7, 537-550, doi: 10.1002/2014ms000356. [Link] 